\title{
Salt overload damages the glycocalyx sodium barrier of vascular endothelium
}

\author{
Hans Oberleithner • Wladimir Peters • \\ Kristina Kusche-Vihrog • Stefanie Korte • \\ Hermann Schillers $\cdot$ Katrin Kliche $\cdot$ Kilian Oberleithner
}

Received: 16 July 2011 / Accepted: 16 July 2011 /Published online: 28 July 2011

(C) The Author(s) 2011. This article is published with open access at Springerlink.com

\begin{abstract}
Sodium overload stiffens vascular endothelial cells in vitro and promotes arterial hypertension in vivo. The hypothesis was tested that the endothelial glycocalyx (eGC), a mesh of anionic biopolymers covering the surface of the endothelium, participates in the stiffening process. By using a mechanical nanosensor, mounted on an atomic force microscope, height $(\sim 400 \mathrm{~nm})$ and stiffness $(\sim 0.25 \mathrm{pN} / \mathrm{nm})$ of the $\mathrm{eGC}$ on the luminal endothelial surface of split-open human umbilical arteries were quantified. In presence of aldosterone, the increase of extracellular sodium concentration from 135 to $150 \mathrm{mM}$ over 5 days (sodium overload) led the eGC shrink by $\sim 50 \%$ and stiffening by $\sim 130 \%$. Quantitative eGC analyses reveal that sodium overload caused a reduction of heparan sulphate residues by $68 \%$ which lead to destabilization and collapse of the eGC. Sodium overload transformed the endothelial cells from a sodium release into a sodiumabsorbing state. Spironolactone, a specific aldosterone antagonist, prevented these changes. We conclude that the endothelial glycocalyx serves as an effective buffer barrier for sodium. Damaged eGC facilitates sodium entry into the
\end{abstract}

H. Oberleithner $(\bowtie) \cdot$ W. Peters $\cdot$ K. Kusche-Vihrog $\cdot$ S. Korte $\cdot$

H. Schillers

Institute of Physiology II, University of Münster,

Robert-Koch-Str. 27b,

48149 Münster, Germany

e-mail: oberlei@uni-muenster.de

K. Kliche

Department of Internal Medicine D, University Hospital Münster,

Münster, Germany

K. Oberleithner

Institute of Fluid Dynamics and Engineering Acoustics,

Technical University Berlin,

Berlin, Germany endothelial cells. This could explain endothelial dysfunction and arterial hypertension observed in sodium abuse.

Keywords Endothelium · Aldosterone - Vascular dysfunction $\cdot$ Sodium channel $\cdot$ Sodium

\section{Introduction}

In many populations worldwide, sodium chloride intake is in the range of 8 to $15 \mathrm{~g}$ per day. This amount contains 3.2 to $6 \mathrm{~g} / \mathrm{d}$ of sodium which is far beyond human needs [24]. There is evidence that sodium is osmotically inactively bound to negatively charged organic material [36]. A potential candidate for such a dynamic sodium store is the glycocalyx (eGC) of blood vessels, which is a negatively charged mesh of membranous glycoproteins, proteoglycans, glycoaminoglycans and associated plasma proteins. Hyaluronic acid and the negatively charged heparan sulphate proteoglycans are its major constituents [39]. eGC lacking hyaluron synthesis lose its vasoprotective function facilitating leukocyte adhesion, inflammation and atherosclerosis [25]. Critical illnesses and major medical interventions can cause eGC shedding followed by severe endothelial dysfunction $[6,26,32]$. Sodium is reversibly bound to this viscoelastic polyelectrolyte [33] and transported via apical plasma membrane sodium channels $(\mathrm{ENaC})$ into the cells, a mechanism mediated by aldosterone [20]. Enhanced sodium influx, triggered by small increases in plasma sodium concentration, directly affects vascular endothelial cells leading to increased mechanical stiffness and reduced nitric oxide release [30].

Initially, during sodium overload, i.e. when sodium intake exceeds the excretory capacity of the kidney, sodium is retained. Repeated recurrence of this process is consid- 
ered to be one of the early steps in the pathogenesis of hypertension and cardiovascular disease [1]. Alternatively, a persistent increase in the plasma level of aldosterone renders vascular endothelium stiff and vulnerable [27]. Changes in mechanical stiffness do not necessarily affect the whole cell, often only the cell's periphery, its "shell" is involved $[17,18,28]$. This part of the cell is close to $1 \mu \mathrm{m}$ thick and comprises the plasma membrane including the highly dynamic submembranous actin web. With atomic force microscopy (AFM), it is now possible to measure the mechanical properties of the cell's shell and to describe saltspecific alterations that occur only in this distinct portion of the cell [29]. As a further step, the work at present has now switched to the soft and barely detectable eGC. Technical limitations were overcome so that the eGC could be quantified in terms of height and stiffness. To mimic physiological conditions, split-open arteries ex vivo were used for eGC stiffness measurements. The data indicate a possible role for the eGC in the maintenance of sodium homeostasis.

\section{Methods}

For technical reasons we used endothelia from ex vivo arteries and two different cell lines. All preparations respond to mineralocorticoids $[11,19,22]$. In order to prevent a collapse of the eGC, we added to all experimental solutions at least $1 \%$ fetal calf serum. In culture media we usually used $20 \%$. In all experiments a basal aldosterone concentration of $0.1 \mathrm{nM}$ and, if appropriate, a spironolactone concentration of $100 \mathrm{nM}$ were used.

\section{Arteries ex vivo}

The preparation of an artery ex vivo obtained from a human umbilical cord is described in Fig. 1. The resected and splitopen artery can be used for mechanical measurements as soon as it is tightly attached to the cell-Tak ${ }^{\circledR}$-coated glass surface. The endothelial cell layer is well preserved in this preparation (over at least 1 week kept in culture) as indicated by immunostaining of VE-cadherin (Fig. 1, lower right). These endothelial cells are called human umbilical artery endothelial cells ex vivo (HUAEC). The mechanical properties of a similar ex vivo artery preparation have been described recently [22].

Endothelial cell culture

Bovine aortic endothelial GM7373 cells (DSMZ, Braunschweig, Germany) were grown in culture as previously described [30]. Briefly, confluent GM7373 cells [16] were cultured in $\mathrm{T}_{25}$ culture flasks using DMEM medium (Invitrogen Corp., Karlsruhe, Germany) with addition of $\mathrm{NaHCO}_{3}$, penicillin $\mathrm{G}$, streptomycin (Biochrom AG, Berlin, Germany) and 20\% fetal bovine serum (PAA Clone, Coelbe, Germany). After reaching confluence cells were split and then cultured on thin (diameter $=15 \mathrm{~mm}$ ) glass coverslips. These were placed in petri dishes filled with culture medium with either low (135 $\mathrm{mM})$ or high $(150 \mathrm{mM})$ sodium. Osmolality was kept constant with appropriate addition of mannitol to the low-sodium medium. GM7373 cells formed confluent monolayers within $48 \mathrm{~h}$ (at $37^{\circ} \mathrm{C}, 5 \% \mathrm{CO}_{2}$ ). For the HUAEC ex vivo preparation, the same culture media were used as described above. The EA.hy926 cell line, derived from endothelium of the human umbilical vein [9], was grown in DMEM medium containing 10\% fetal calf serum (Biochrom AG).

\section{Intracellular sodium measurements}

Intracellular sodium measurements were performed on confluent EA.hy926 cell layers seeded on glass bottom dishes (Willco Wells, Amsterdam, Netherlands) mounted to an inverted fluorescence microscope (Zeiss Axiovert 200, Jena, Germany) and equipped with a CCD camera (CoolSNAP; Visitron Systems, Munich, Germany). The AMester of the intracellular sodium probe SBFI (sodiumbinding benzofuran isophthalate; Molecular Probes, Darmstadt, Germany) was dissolved in DMSO (5 mM) and mixed with an equal volume of $25 \% \mathrm{wt} / \mathrm{vol}$ Pluronic- 127 dissolved in DMSO. Endothelial cell monolayers on glass were incubated with a final SBFI concentration of $0.01 \mathrm{mM}$ in HEPES-buffered medium for at least $3 \mathrm{~h}$ at $4^{\circ} \mathrm{C}$. For fluorescence measurements a $75-\mathrm{W}$ Xenon light source and a 340/380-nm filter set was applied. After loading, EA. hy926 were perfused at room temperature for 30 min with dye-free HEPES buffer containing $5 \mathrm{mM}$ glucose, $10 \mathrm{mM}$ HEPES, $5 \mathrm{mM} \mathrm{KCl}, 1 \mathrm{mM} \mathrm{CaCl}_{2}, 1 \mathrm{mM} \mathrm{MgCl} 2$, and $135 \mathrm{mM} \mathrm{NaCl}\left(\right.$ low $\mathrm{Na}^{+}$) or $150 \mathrm{mM} \mathrm{NaCl}\left(\right.$ high $\mathrm{Na}^{+}$), respectively. Then, cells were incubated in low or high $\mathrm{Na}^{+}$ solution containing Heparinase I $(1 \mathrm{U} / \mathrm{ml}$; Sigma-Aldrich Chemie $\mathrm{GmbH}$, Steinheim, Germany) for $20 \mathrm{~min}$, while fluorescence measurements were taken every $10 \mathrm{~s}$. At the end of the experiment, intracellular calibration for sodium was performed as described previously [23].

\section{Extracellular sodium measurements}

GM7373 cells were cultured as described above. After removal of the medium and washing twice with phosphatebuffered saline, $5.5 \mathrm{ml}$ of HEPES-buffered saline [composition in $\mathrm{mM}: 140 \mathrm{NaCl}, 5 \mathrm{KCl}, 1 \mathrm{MgCl}_{2}, 1 \mathrm{CaCl}_{2}$, and 10 HEPES ( $N$-2-hydroxyethylpiperazine- $N$ '-2-ethanesulfonic acid), $\mathrm{pH} 7.4$ ] containing $0.5 \mathrm{U} / \mathrm{ml}$ heparinase I was added 
Fig. 1 Preparation of an artery ex vivo obtained from a human umbilical cord. Upper left one of the two umbilical arteries freed from the surrounding tissue. Upper right a glass cover slip, coated with Cell-Tak ${ }^{\circledR}$ within the boundaries of the black circle is positioned underneath the cut-open artery. Lower left split-open artery (about $2 \times$ $0.5 \mathrm{~mm}$ ), with the endothelial surface facing upwards, after 1 week in culture. Lower right immunostaining of VE-cadherin in an ex vivo preparation cultured for 7 days
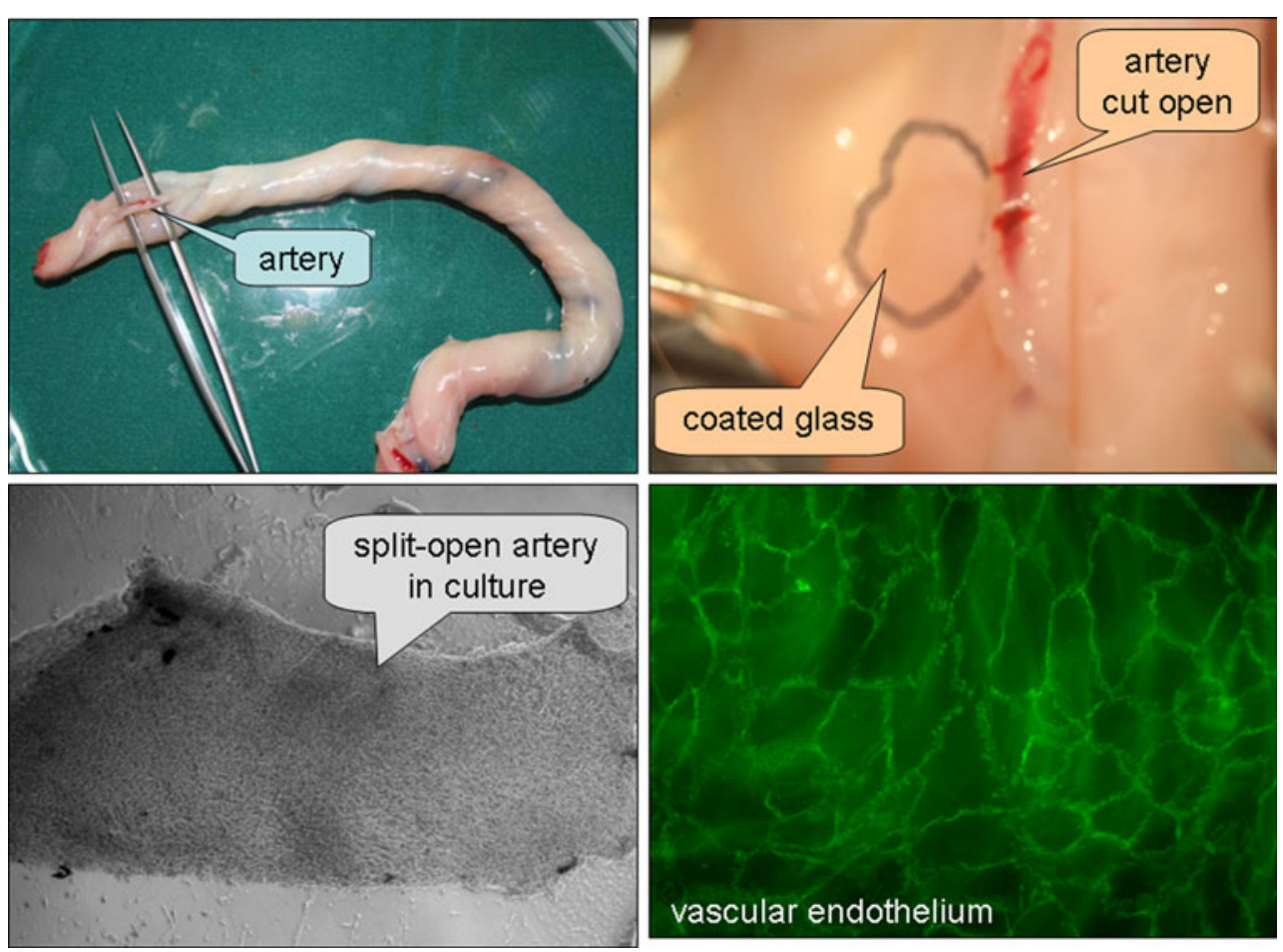

to the confluent cell monolayer $\left(75 \mathrm{~cm}^{2}\right)$ and incubated at $37^{\circ} \mathrm{C}$. The culture flasks were placed on a shaker inside the $\left(\mathrm{CO}_{2}\right.$ free $)$ incubator and rhythmically shaken along the longitudinal axis of the flask $(0.5 \mathrm{~Hz})$ for $30 \mathrm{~min}$. Low/high sodium (see above), aldosterone, spironolactone, amiloride, and the respective solvents were present in the different media as appropriate. After incubation the respective supernatants were harvested and centrifuged $(134 \times g)$, and the $\mathrm{pH}$ titrated to 5.5 by means of $0.1 \mathrm{M} \mathrm{HCl}$. This strategy was used to release as much sodium as possible from the binding sites of the heparan sulphate residues. Finally, sodium was measured by using an electrolyte analyzer (EML 105; Radiometer, Copenhagen). Aldosterone ( $d$-aldosterone, Sigma-Aldrich) and spironolactone (Sigma-Aldrich) were dissolved in ethanol $(1 \mathrm{mM}$ stock solution, stored at $4^{\circ} \mathrm{C}$ ). A concentration of $0.1 \mathrm{nM}$ aldosterone and $100 \mathrm{nM}$ spironolactone was used in the culture and perfusion media as appropriate. Amiloride (Sigma-Aldrich), a selective blocking chemical of the ENaC, was dissolved in water, at a final concentration of $10 \mu \mathrm{mol} / \mathrm{l}$.

\section{eGC stiffness measurements}

Figure 2 schematically describes stiffness measurements in living vascular endothelium. The figure explains the method of "mechanical cell sectioning", from the cell surface towards the cell interior. In a previous publication, we described stiffness measurements of the "bulk" cell membrane (including the glycocalyx, the plasma membrane and the cortical actin web) and the "bulk" cell [30]. In the present study we did not measure bulk stiffnesses but instead exclusively focused on stiffness measurements of the outer surface layer of the endothelial cells, the eGC.

eGC stiffness of ex vivo arteries was determined with AFM techniques similar as described previously in detail for measuring the endothelial cell membrane/cortical web [28]. The following modifications were necessary for eGC stiffness measurements: (1) low indentation velocity, $400 \mathrm{~nm} / \mathrm{s}$; (2) low loading force, about $200 \mathrm{pN}$; and (3) low indentation frequency, $0.2 \mathrm{~Hz}$. AFM cantilevers (MLCT contact microlevers; spring constant, $0.01 \mathrm{~N} / \mathrm{m}$; Veeco, Mannheim, Germany) with colloidal tips (electrically uncharged polystyrene spheres, $1 \mu \mathrm{m}$ in diameter) were applied [5]. AFM measurements were performed at $37^{\circ} \mathrm{C}$ using a Multimode ${ }^{\circledR}$ AFM with a feedback-controlled heating device (Veeco). The artery preparation was bathed in HEPES-buffered solution [standard composition in millimolars: $135 \mathrm{NaCl}, 5 \mathrm{KCl}, 1 \mathrm{MgCl}_{2}, 1 \mathrm{CaCl}_{2}, 10$ HEPES ( $N$-2-hydroxyethylpiperazine- $N$ '-2-ethanesulfonic acid), $\mathrm{pH}$ 7.4]. Fetal bovine serum (1\%) was added in order to prevent eGC collapse [12, 35]. Sodium (135$150 \mathrm{mM}$ ) was varied as appropriate. Iso-osmolality was maintained by the addition of mannitol.

Simultaneous AFM stiffness and immunofluorescence measurements

Stiffness measurements and fluorescence microscopy on the endothelial glycocalyx were performed by an AFM (BioScope Catalyst, Bruker, Mannheim, Germany) com- 
Fig. 2 Schematic illustration of the indentation procedure (mechanical cell sectioning). The cell is modelled to have three mechanically measurable layers, the glycocalyx, the plasma membrane including the cortical web and the bulk phase of the cell cytosol. a The colloidal AFM tip is positioned above the living cell.

b Indentation of the glycocalyx (this mode is used in the present study). c Indentation of glycocalyx, plasma membrane and actin web. d Indentation of the glycocalyx, the plasma membrane including the cortical actin web and the cell cytosol (bulk cell indentation)

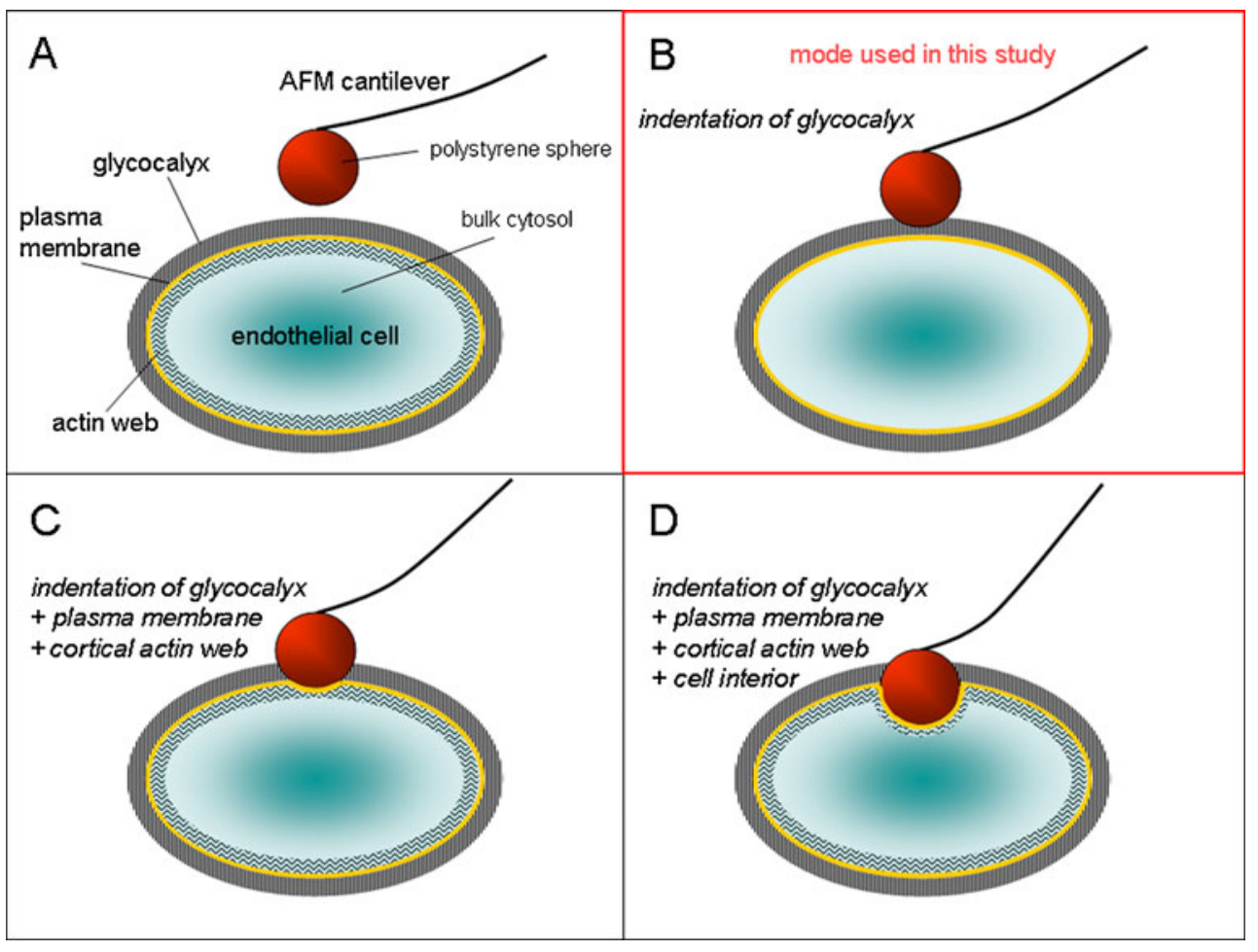

bined with an inverted fluorescence microscope (DMI 6000 B; Leica Microsystems, Wetzlar, Germany). The mechanical and optical measurements were simultaneously performed on living cells in HEPES-buffered solution, containing 1\% FCS (PAA Clone). For the AFM stiffness measurements soft cantilevers (spring constant $=18 \mathrm{pN} / \mathrm{nm}$; Novascan, Ames, IA, USA) with spherical tips (sphere diameter $=1 \mu \mathrm{m}$ ) and maximal loading forces in the range of $400 \mathrm{pN}$ were used.

Heparan sulphate of the eGC was quantified by using a mouse anti-heparan sulphate (10E4 epitope) antibody (Seikagaku Corporation, Tokyo, Japan). As secondary antibody, QDot 655 goat anti-mouse antibody conjugate (Invitrogen, Darmstadt, Germany) was used. The primary antibody in the dilution of 1:500 was added to living GM7373 cells maintained in culture medium at $37^{\circ} \mathrm{C}$. After incubation for $30 \mathrm{~min}$, cells were washed $3 \times 5 \mathrm{~min}$ with PBS (PAA Clone) at $37^{\circ} \mathrm{C}$. Then the secondary QDot antibody conjugate was added (1:800). The cells were again incubated for $30 \mathrm{~min}$ and washed $3 \times 5 \mathrm{~min}$ in $\mathrm{PBS}$ at $37^{\circ} \mathrm{C}$. Then, PBS was exchanged by HEPES-buffered solution, containing 1\% FCS (PAA Clone) and the measurement started immediately after this procedure. Quantitative fluorescence microscopy was performed. The QDots (i.e. fluorescent nanocrystals that virtually do not bleach) were excited with a 400-nm laser (emission wavelength, $655 \mathrm{~nm}$ ). The number of bound QDots/area was quantified at $\times 100$ magnification as previously described [22]. The amount of stained heparan sulphate was quantified by counting single Qdots per area (about 5 to 10 cells per area). In order to account for any variations in cell height, two to four images at different focal planes per area were taken and the total amount of Qdots determined. The fluorescence data were processed with ImageJ, version 1.43U (freeware, http://rsbweb.nih.gov/ij/). Stiffness, height and heparan sulphate-bound QDots were quantified before and after addition of heparinase I (45 min incubation, $1 \mathrm{mU} / \mathrm{ml}$ ). AFM raw data were processed with Punias 3D version 1.0 release 1.1 (http://punias.voila.net/). For graphical and statistical exploration, STATISTICA 8 (StatSoft Inc., Tulsa, USA) and OriginPro 8 (OriginLab Corporation, Northampton, USA) were used.

\section{Glycocalyx staining with Ulex europaeus agglutinin I}

EA.hy926 cells were seeded on $\varnothing 35 \mathrm{~mm}$ culture dishes with glass bottom (Wilco, Amsterdam, Netherlands) and grown for 5 days in low- and high-sodium medium (in presence of $0.1 \mathrm{nM}$ aldosterone) until confluence was reached. Fluorescein-labelled U. europaeus agglutinin I (Vector Laboratories, Burlingame, USA) in a concentration of $0.01 \mathrm{mg} / \mathrm{ml}$ was added directly to the cell medium. After $10 \mathrm{~min}$ of incubation, cells were washed twice with HEPES-buffered (low sodium/high sodium $+0.1 \mathrm{nM}$ aldosterone $+1 \%$ FCS) solution. For fluorescence, excitation wavelength of $494 \mathrm{~nm}$ was used; emission at $518 \mathrm{~nm}$ was measured. Fluorescence microscopy (excitation/emission wavelengths in nanometers, 494/518) was performed 
by a Leica DMI 6000 B inverted fluorescence microscope ( $\times 40$ magnification; Leica Microsystems). The fluorescence data were processed with ImageJ (see above).

\section{Results}

Nanoindentations disclose a soft endothelial surface layer

In order to measure the stiffness of the extremely soft eGC, several experimental parameters had to be modified, in comparison to the standard nanoindentation procedures (described in methods). Figure 3 shows a representative force-distance curve. Two slopes can be detected, the first slope is shallow and the second slope is steep. As indicated above, the slopes directly reflect the regional (zonal) cell stiffnesses. Thus, there is a soft outer surface layer (indicated by the first slope), directly adjacent to a more stiff layer underneath. Figure 4 displays time-resolved data from a representative experiment in which heparinase was applied in order to biochemically characterize the first surface layer. Within minutes of heparinase treatment, the stiffness of the outer cell layer decreases by more than $50 \%$ indicating cleavage of heparan sulphate residues. At the same time, the glycocalyx thickness in this particular experiment drops from 400 to $200 \mathrm{~nm}$, consistent with the view that a lack of heparan sulphate residues in this surface layer leads to a collapse of this structure. Taken together, this strongly suggests that the first mechanical resistivity which has to be overcome by the colloidal AFM tip during the indentation procedure most probably is the endothelial glycocalyx.

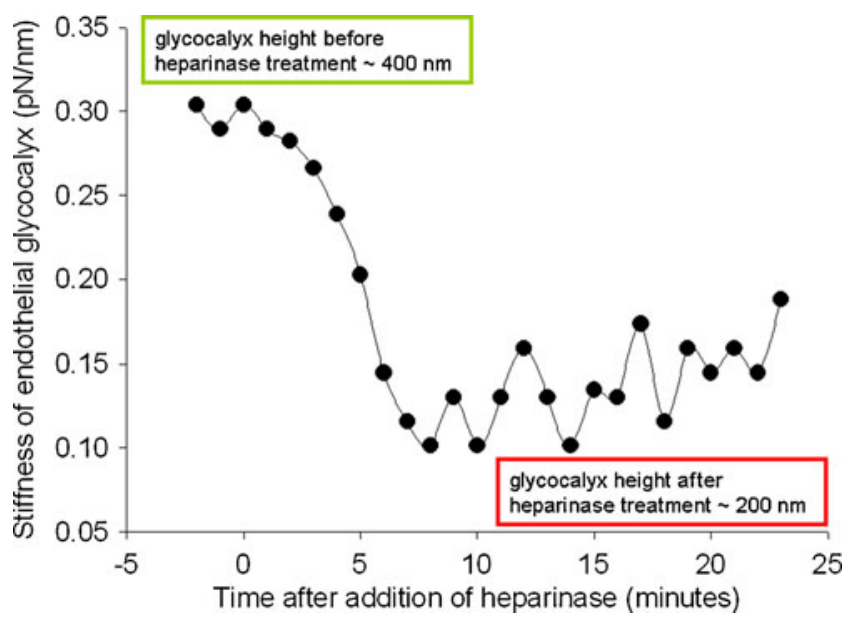

Fig. 4 Decrease of eGC stiffness in response to heparan sulphate digestion. Height measurements were derived from the force-distance curves before and after heparinase treatment. The experiment was performed in an ex vivo artery

Proof of principle that the endothelial surface layer detected by $\mathrm{AFM}$ is the eGC

To test the assumption that the indentation measurements indeed are able to disclose the eGC, we combined mechanical and fluorescence measurements in individual cells. Using a hybrid AFM fluorescence setup [4, 10], we measured stiffness/height of the soft surface layer and, simultaneously in the same cell, the amount of heparan sulphate using quantitative immunofluorescence. The measurements were performed before and $45 \mathrm{~min}$ after heparinase treatment. This approach allows the quantification of surface layer stiffness, height and heparan sulphate in

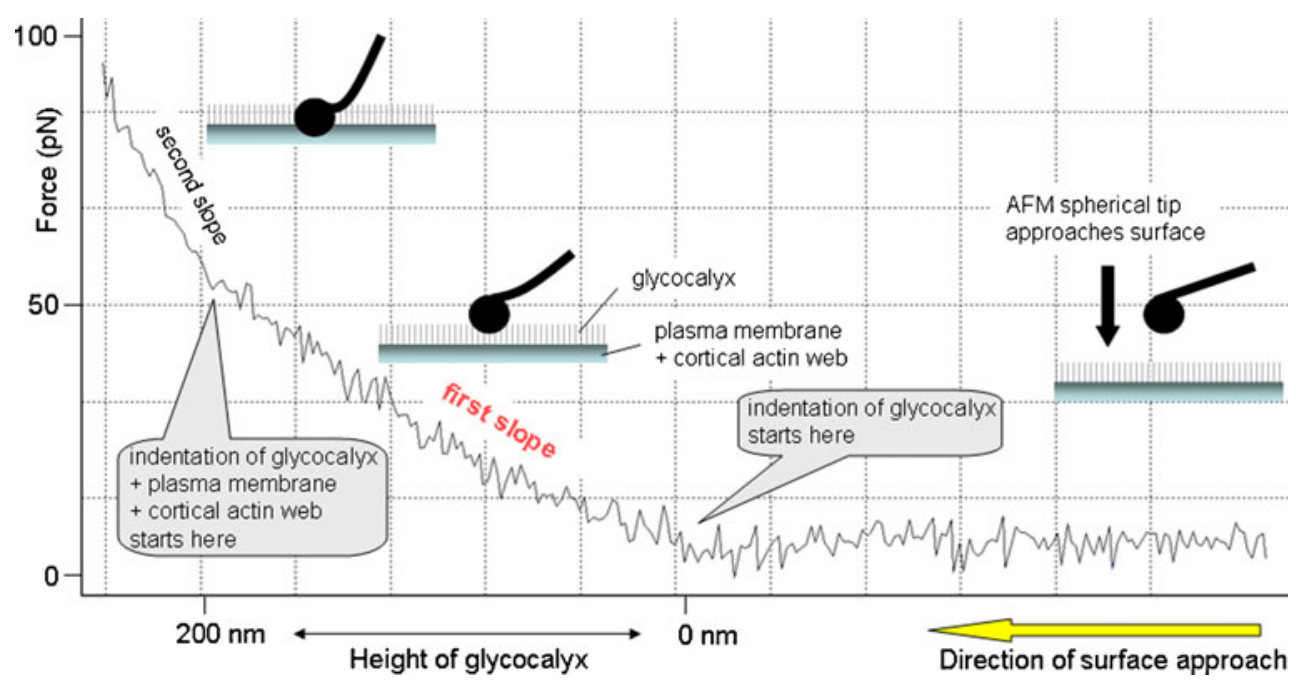

Fig. 3 Original tracing representing a force-distance curve performed on the endothelial surface of an ex vivo artery. The first slope indicates the stiffness of the very first layer, most likely the endothelial glycocalyx (eGC). The second slope indicates the stiffness of the plasma membrane and the cortical actin web. The distance between the starting point of eGC indentation and the starting point of the second slope (projected to the $x$-axis) corresponds to the height (thickness) of the eGC (in this trace about $200 \mathrm{~nm}$ ). The insets illustrate the different positions of the colloidal AFM tip during the cell indentation process 
individual cells (paired data). The data are displayed in Fig. 5. It is evident that heparinase treatment leads to a decrease of stiffness (47\%), height (42\%) and heparan sulphate (34\%). The decrease of heparan sulphate significantly correlates with the decrease in stiffness (Spearman correlation coefficient $=0.72, p<0.001$ ) and height (correlation coefficient $=0.38, p<0.001$ ). Taken together the data strongly support the view that the soft endothelial surface layer, disclosed by the nanoindentation measurements, is indeed the eGC.

\section{Sodium alters the eGC}

The present study focuses on the mechanical stability of the eGC. Its mechanical stiffness is about $0.25 \mathrm{pN} / \mathrm{nm}$ which is 5 to 10 times smaller than the stiffness of the plasma membrane (including the submembrane actin web) [28]. eGC stiffness strongly depends upon ambient sodium. eGC of endothelium, maintained in high-sodium conditions for 5 days, (sodium overload), hardens, and heparinase treatment is less effective (low sodium, $58 \%$ decrease in stiffness; high sodium, $35 \%$ decrease in stiffness). Spironolactone, a specific aldosterone antagonist added in the culture medium during the 5-day high-sodium incubation period, completely prevents the effects of sodium overload, i.e. the eGC remains soft and avidly responds to heparinase (Fig. 6).

As indicated in Fig. 3, eGC height and stiffness can be taken from the force-distance curves of individual cells. These two parameters are plotted in Fig. 7. When the sodium concentration has been kept low in the culture

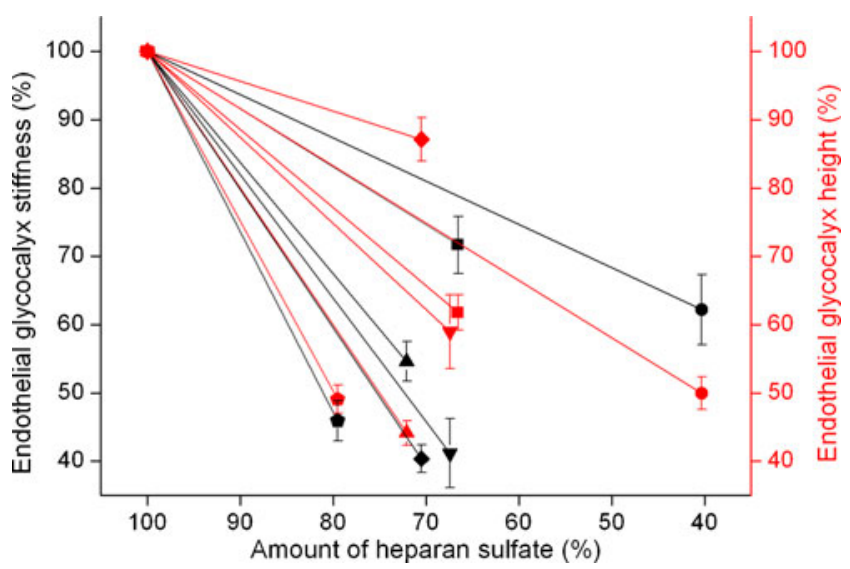

Fig. 5 Combined AFM fluorescence measurements in living human vascular endothelial cells (EA.hy926). Relative stiffness (black symbols) and height (red symbols) values of the endothelial glycocalyx were plotted as a function of the amount of heparan sulphate before $(100 \%)$ and after $45 \mathrm{~min}$ of heparinase treatment (normalized mean \pm SE, $n=7-39$ force-distance cycles per cell; each symbol represents one individual cell). Mechanical (stiffness/height) and immunofluorescence (heparan sulphate) measurements were performed simultaneously on individual cells (paired data)

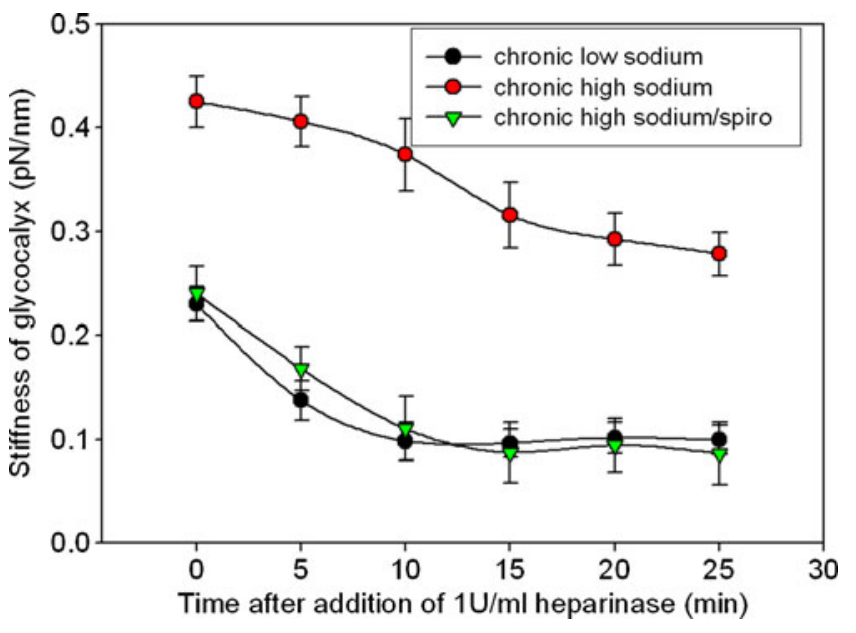

Fig. 6 Time course of changes in eGC stiffness induced by the addition of heparinase. Experiments were performed in arteries ex vivo exposed for 1 week to low $(135 \mathrm{mM})$ sodium, high $(150 \mathrm{mM})$ sodium and high sodium plus spironolactone $(100 \mathrm{nM})$. Aldosterone $(0.1 \mathrm{nM})$ was present in all media. Stiffness measurements in the different groups were performed in identical perfusion media (normal sodium)

medium for 5 days, eGC is found soft and prominent. In contrast, when the sodium concentration has been kept high for 5 days, the eGC hardens and flattens. Again, spironolactone prevents the high-sodium response of the eGC.

Taken together, the data indicate that the eGC structure is severely altered when the endothelium is chronically exposed to ambient high sodium.

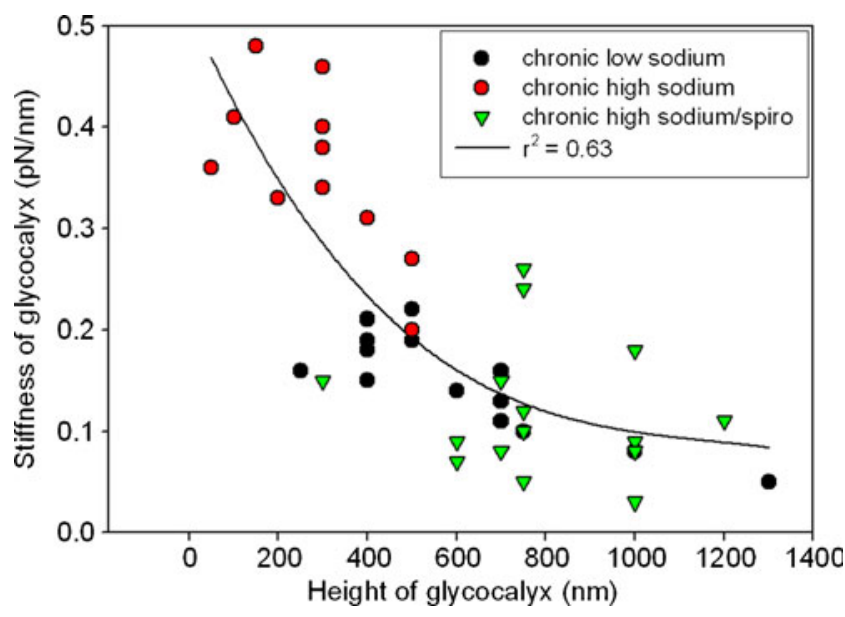

Fig. 7 Correlation between eGC stiffness and eGC height. Experiments were performed in arteries ex vivo exposed for 1 week to low $(135 \mathrm{mM})$ sodium, high $(150 \mathrm{mM})$ sodium and high sodium plus spironolactone $(100 \mathrm{nM})$. Low-sodium treatment results in a thick and soft eGC. High-sodium incubation (sodium overload) results in reduced eGC height and increased eGC stiffness. The latter effects are blocked by the aldosterone antagonist spironolactone. Aldosterone $(0.1 \mathrm{nM})$ was present in all media. Stiffness/height measurements in the different experimental series were performed in identical perfusion media (normal sodium) 
Quantifying eGC proteoglycans by fluorescence measurements

To complement the AFM data and thus gaining more insight into any specific alterations of the glycocalyx, we quantified endothelial-specific lectin binding using fluorescence-labelled $U$. europaeus agglutinin I (UEA) and heparan sulphate residues using specific antibodies labelled with fluorescent quantum dots (nanocrystals). Two experimental series in cultured human endothelial cells (EAhy.926 cell line) were performed, one after low-sodium and one after high-sodium incubation (5 days of incubation). The data are shown in Fig. 8. There was a dramatic decrease of heparan sulphate fluorescence in cells incubated in ambient high sodium indicating a $68 \%$ decrease in the amount of heparan sulphate residues (Fig. 8, upper graph). This finding may explain the reduced response of eGC stiffness to heparinase as shown in Fig. 6. In contrast, UEA binding rather increased in ambient high sodium (by about 21\%; Fig. 8, lower graph). This could be explained either by an absolute increase in lectin binding sites or, more likely, by a better accessibility of the core protein binding sites to UEA due to the dramatic heparan sulphate rarefication that occurred within 5 days of sodium overload.
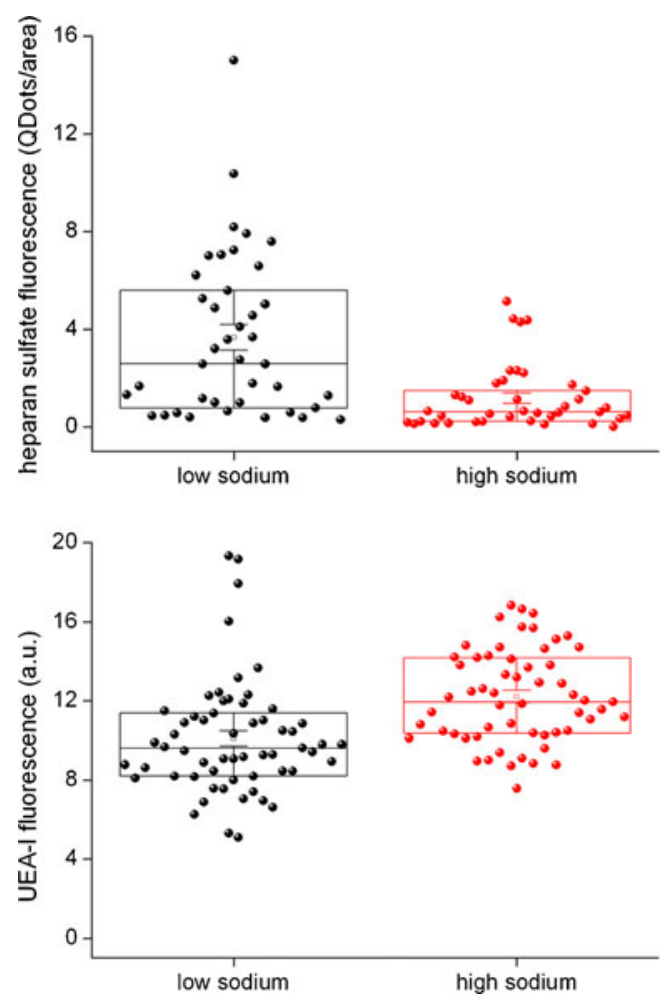

Fig. 8 Quantitative analyses of heparan sulphate immunofluorescence (quantum dots/area). Cells (EA.hy926) were chronically exposed ( 5 days in culture) to either ambient low sodium (135 mM) or high sodium $(150 \mathrm{mM})$. Aldosterone $(0.1 \mathrm{nM})$ was present in all media. The statistical difference between low sodium and high sodium is significant $(p<0.01$, Mann-Whitney $U$ test $)$
Taken together, the data indicate that high-sodium treatment leads to a reduction in eGC heparan sulphate residues. This destabilizes the eGC structure and finally leads to eGC collapse.

Endothelial sodium transport depends upon eGC

A sodium assay system was developed to test whether the eGC is able to store sodium in measurable amounts. Human vascular endothelial cells (EAhy-926) were cultured for 1 week under three different conditions, low sodium, high sodium and high sodium + spironolactone. The cells were then exposed to heparinase for $60 \mathrm{~min}$, and, subsequently, the change in sodium concentration in the supernatant was measured. In response to heparinase treatment, endothelial cells cultured in low-sodium medium release about $16 \mathrm{nmol}$ sodium per $\mathrm{cm}^{2}$ into the supernatant (Fig. 9). In contrast, endothelial cells cultured in high sodium do not show any net release of sodium but, surprisingly, increase their content of sodium. Spironolactone prevents this increase. In addition, intracellular sodium was measured in cells, cultured in ambient low sodium and high sodium, before and $20 \mathrm{~min}$ after exposure to heparinase. In cells cultured in low-sodium medium, intracellular sodium concentration averaged $13.4 \pm 2.33 \mathrm{mM}$ and decreased to $8.8 \pm 0.93 \mathrm{mM}$ after heparinase treatment (delta sodium= $4.6 \pm 1.51 \mathrm{mM}, p<0.02)$. In contrast, in cells cultured in high-sodium medium, intracellular sodium concentration

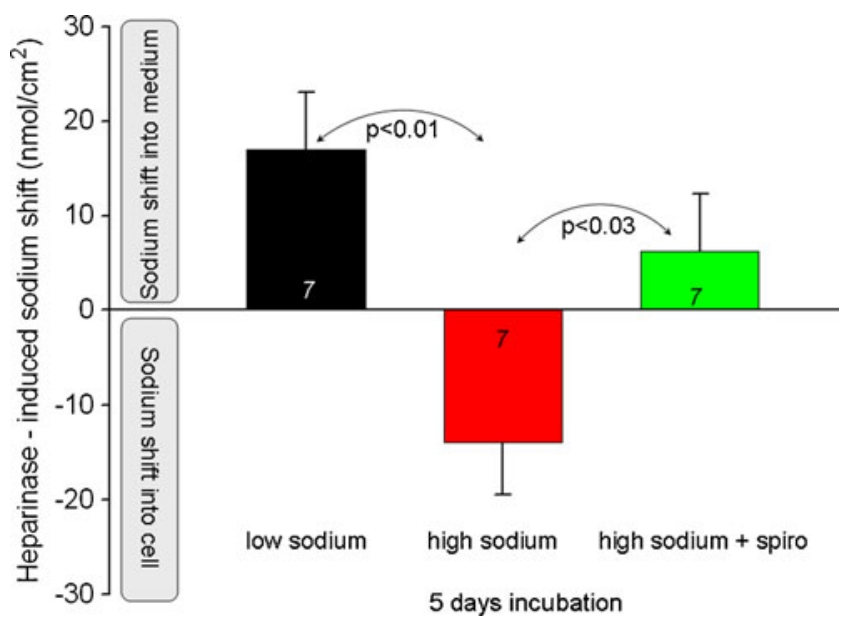

Fig. 9 Heparinase-induced shift of sodium obtained in cultured bovine endothelial cells from aorta (GM7373 cells). Endothelial culture exposed to a low-sodium medium for 1 week releases about $16 \mathrm{nmol}$ of sodium per $\mathrm{cm}^{2}$ into the supernatant within $30 \mathrm{~min}$ of heparinase treatment. In contrast, when the endothelium was incubated for 5 days in high-sodium medium (sodium overload), $13 \mathrm{nmol}$ of sodium per $\mathrm{cm}^{2}$ "disappears" from the supernatant into the endothelial monolayer after heparinase treatment. Spironolactone $(100 \mathrm{nM})$ prevents this response. Aldosterone $(0.1 \mathrm{nM})$ was present in all media. Sodium flux measurements in the different groups were performed in identical perfusion media (normal sodium) 
averaged $8.8 \pm 1.39 \mathrm{mM}$ and increased to $11.6 \pm 1.91 \mathrm{mM}$ after heparinase treatment (delta sodium $=2.8 \pm 0.89 \mathrm{mM}$, $p<0.01$ ). Taken together, the data indicate that the eGC is a barrier limiting sodium movement between blood and endothelium. The direction of net sodium movement after heparan sulphate depletion depends on the concentration of ambient sodium to which cells were chronically exposed to during culture.

\section{Discussion}

The eGC serves important functions in the vascular system [39]. It regulates vascular permeability [34, 37], controls flow- and pressure- induced mechanotransduction of the endothelium [40] and plays a potentially crucial role in the pathogenesis of inflammation $[6,26]$. Chemically, the eGC is an anionic biopolymer with viscoelastic and specific ionbinding properties [33]. Proteoheparan sulphate macromolecules, anchored in the plasma membrane, expose negatively charged glycosaminoglycan side chains with binding sites for inorganic cations. Calcium ions control the conformational structure of the eGC so that sodium ions are preferentially absorbed [2, 33]. There is evidence that sodium may play a key role in the regulation of blood flow and arterial blood pressure. It was shown that small changes in extracellular sodium evoke large increases of systolic blood pressure [13]. The eGC was identified as a blood flow sensor where sodium flux into the endothelial cells was thought to be a crucial trigger mechanism that initiates intracellular signalling [33]. More recently, the eGC was modelled as a mechanotransducer of fluid shear stress involving the fine actin web located underneath the apical plasma membrane [31, 40]. Moreover, it was shown that the "outer shell" of the cell, comprising the eGC, the apical plasma membrane and the cortical actin web underneath the apical cell membrane, is an "ion sensitive zone" [28]. Changes in mechanical stiffness of this outer (apical) cell zone are physiologically relevant since they determine the deformation of the cell surface induced by shear stress and thus the release of nitric oxide, one of the major regulators of vascular tone [29]. In contrast to the fine subapical actin web that determines "local surface elasticity" and thus nitric oxide synthase activity, the coarse actin shear fibres located at the cell basis and anchored to focal adhesions are essential for the alignment in the direction of flow [3, 8].

The eGC is modified by ambient sodium

In the present study, efforts have been made to evaluate the height, stiffness and sodium-binding capacity of the eGC. Stiffness and height were measured in arteries ex vivo in physiological conditions, and sodium storage capacity was estimated in cultured endothelial monolayers. Sodium overload for 5 days hardens and flattens the eGC. This is disadvantageous for humans, since deterioration of the eGC initiates a breakdown of the vascular barrier similar to that in inflammation [6]. Aldosterone sensitizes endothelial cells to high sodium by inserting epithelial sodium channels into the plasma membrane $[7,15,21]$ which allows sodium to enter the cells and disturb cellular function [30].

There is an apparent discrepancy between the heparinase-induced eGC damage (stiffness decrease and height decrease, Fig. 4) and eGC damage caused by sodium overload (stiffness increase and height decrease, Fig. 6). In both experiments the glycocalyx obviously collapses (height decrease) due to the lack of heparan sulphates. A possible explanation is that acute heparan sulphate removal (heparinase treatment for $45 \mathrm{~min}$ ) leads to eGC collapse without any structural reorganisation while sodium overload for 5 days, paralleled by eGC damage, allows some still unknown reorganisation processes (e.g. compacting) of the altered eGC. Gao and Lipowsky [14] made comparable observations studying post-capillary venules using intravital microscopy. They showed that the removal of heparan sulphate causes a collapse of the glycocalyx most likely due to a breakdown of the fibre matrix. They concluded that the heparan sulphate residues could provide the structural support for the eGC.

It is possible that the eGC plays a crucial role as a barrier for sodium, e.g. when the eGC is prominent ( $400 \mathrm{~nm}$ thick) and endothelial sodium channel expression is low-a condition most likely achieved in humans with low salt intake - two barriers in series, namely the eGC and the plasma membrane, prevent sodium accessing the endothelial cells. In contrast, when the eGC is virtually collapsed $(<200 \mathrm{~nm})$ and the expression of sodium channels is high - a condition to be expected in humans with high salt intake - the two-barrier mechanism increasingly fails and gradually cells may become accessible to sodium.

eGC is a significant endothelial sodium barrier

Challenging the eGC with heparinase weakens endothelial barrier function for sodium. After heparinase application, cells cultured in low-sodium medium for 5 days release sodium into the extracellular compartment while, in contrast, cells cultured in high-sodium medium take up sodium from the extracellular fluid. These sodium flux measurements (Fig. 9) are paralleled by mirror-like changes of intracellular sodium. It appears that removal of heparan sulphate from the eGC unmasks sodium shuffle mechanisms between the blood compartment and the endothelium. Although not yet proven, it is likely that, after removal of the glycocalyx, the sodium pump (i.e. the sodium/ 
potassium ATPase) is more active in the low-sodium adapted cells while, in contrast, the passive sodium leak through sodium channels (directed into the cell) dominates in the high-sodium adapted cells. It is tempting to speculate that in the salt-loaded organism, sodium may more easily move from blood into the perivascular space whereby escaping renal filtration and subsequently damaging the whole organism [24].

\section{Clinical perspective}

Sodium abuse is common in many populations worldwide, causing severe health problems. Derived from the present in vitro experiments, it is tempting to speculate that high sodium intake weakens the protective eGC buffer barrier in the human organism. Thus, sodium arriving in the blood after a salty meal more readily exits the vascular system. It distributes in the extracellular space where it binds, osmotically inactive, to negatively charged organic matrices [36]. Thereby, ingested sodium escapes the immediate clearance by the kidneys accumulating over time in the tissue if sodium intake is chronically high. The high sodium content in the body will finally damage the organism [38].

Acknowledgements We thank Prof. Hugh de Wardener for the critical reading of the manuscript and Leo Jeggle and Marianne Wilhelmi for helping to develop the ex vivo artery preparation. Work was supported by grants from the Deutsche Forschungsgemeinschaft (OB 63/17-1 and Koselleck-grant OB 63/18).

Declaration The authors declare that they have no conflict of interest.

Open Access This article is distributed under the terms of the Creative Commons Attribution Noncommercial License which permits any noncommercial use, distribution, and reproduction in any medium, provided the original author(s) and source are credited.

\section{References}

1. Adrogue HJ, Madias NE (2007) Sodium and potassium in the pathogenesis of hypertension. N Engl J Med 356:1966-1978

2. Bevan JA (1993) Flow regulation of vascular tone. Its sensitivity to changes in sodium and calcium. Hypertension 22:273-281

3. Boon RA, Leyen TA, Fontijn RD, Fledderus JO, Baggen JM, Volger OL, van Nieuw Amerongen GP, Horrevoets AJ (2010) KLF2-induced actin shear fibers control both alignment to flow and JNK signaling in vascular endothelium. Blood 115:25332542

4. Callies C, Schon P, Liashkovich I, Stock C, Kusche-Vihrog K, Fels J, Strater AS, Oberleithner H (2009) Simultaneous mechanical stiffness and electrical potential measurements of living vascular endothelial cells using combined atomic force and epifluorescence microscopy. Nanotechnology 20:1-8

5. Carl P, Schillers H (2008) Elasticity measurement of living cells with an atomic force microscope: data acquisition and processing. Pflugers Arch 457:551-559
6. Chappell D, Westphal M, Jacob M (2009) The impact of the glycocalyx on microcirculatory oxygen distribution in critical illness. Curr Opin Anaesthesiol 22:155-162

7. Chen W, Valamanesh F, Mirshahi T, Soria J, Tang R, Agarwal MK, Mirshahi M (2004) Aldosterone signaling modifies capillary formation by human bone marrow endothelial cells. Vascul Pharmacol 40:269-277

8. Dekker RJ, Van SS, Fontijn RD, Salamanca S, de Groot PG, VanBavel E, Pannekoek H, Horrevoets AJ (2002) Prolonged fluid shear stress induces a distinct set of endothelial cell genes, most specifically lung Kruppel-like factor (KLF2). Blood 100:16891698

9. Edgell CJ, Haizlip JE, Bagnell CR, Packenham JP, Harrison P, Wilbourn B, Madden VJ (1990) Endothelium specific WeibelPalade bodies in a continuous human cell line, EA.hy926. In Vitro Cell Dev Biol 26:1167-1172

10. Fels J, Callies C, Kusche-Vihrog K, Oberleithner H (2010) Nitric oxide release follows endothelial nanomechanics and not vice versa. Pflugers Arch 460:915-923

11. Fels J, Oberleithner H, Kusche-Vihrog K (2010) Menage a trois: aldosterone, sodium and nitric oxide in vascular endothelium. Biochim Biophys Acta 1802:1193-1212

12. Florian JA, Kosky JR, Ainslie K, Pang Z, Dull RO, Tarbell JM (2003) Heparan sulfate proteoglycan is a mechanosensor on endothelial cells. Circ Res 93:e136-e142

13. Friedman SM, McIndoe RA, Tanaka M (1990) The relation of blood sodium concentration to blood pressure in the rat. J Hypertens 8:61-66

14. Gao L, Lipowsky HH (2010) Composition of the endothelial glycocalyx and its relation to its thickness and diffusion of small solutes. Microvasc Res 80:394-401

15. Golestaneh N, Klein C, Valamanesh F, Suarez G, Agarwal MK, Mirshahi M (2001) Mineralocorticoid receptor-mediated signaling regulates the ion gated sodium channel in vascular endothelial cells and requires an intact cytoskeleton. Biochem Biophys Res Commun 280:1300-1306

16. Grinspan JB, Mueller SN, Levine EM (1983) Bovine endothelial cells transformed in vitro by benzo(a)pyrene. J Cell Physiol 114:328-338

17. Iyer S, Gaikwad RM, Subba-Rao V, Woodworth CD, Sokolov I (2009) Atomic force microscopy detects differences in the surface brush of normal and cancerous cells. Nat Nanotechnol 4:389-393

18. Kasas S, Wang X, Hirling H, Marsault R, Huni B, Yersin A, Regazzi R, Grenningloh G, Riederer B, Forro L, Dietler G, Catsicas S (2005) Superficial and deep changes of cellular mechanical properties following cytoskeleton disassembly. Cell Motil Cytoskeleton 62:124-132

19. Kliche K, Jeggle P, Pavenstadt H, Oberleithner H (2011) Role of cellular mechanics in the function and life span of vascular endothelium. Pflugers Arch 462:209-217

20. Kusche-Vihrog K, Callies C, Fels J, Oberleithner H (2010) The epithelial sodium channel $(\mathrm{ENaC})$ : mediator of the aldosterone response in the vascular endothelium? Steroids 75:544-549

21. Kusche-Vihrog K, Sobczak K, Bangel N, Wilhelmi M, Nechyporuk-Zloy V, Schwab A, Schillers H, Oberleithner H (2008) Aldosterone and amiloride alter $\mathrm{ENaC}$ abundance in vascular endothelium. Pflugers Arch 455:849-857

22. Kusche-Vihrog K, Urbanova K, Blanque A, Wilhelmi M, Schillers H, Kliche K, Pavenstadt H, Brand E, Oberleithner H (2011) Creactive protein makes human endothelium stiff and tight. Hypertension 57:231-237

23. Maier LS, Pieske B, Allen DG (1997) Influence of stimulation frequency on $\left[\mathrm{Na}^{+}\right] \mathrm{i}$ and contractile function in Langendorffperfused rat heart. Am J Physiol 273:H1246-H1254

24. Meneton P, Jeunemaitre $X$, de Wardener HE, MacGregor GA (2005) Links between dietary salt intake, renal salt handling, 
blood pressure, and cardiovascular diseases. Physiol Rev 85:679715

25. Nagy N, Freudenberger T, Melchior-Becker A, Rock K, Ter BM, Jastrow H, Kinzig M, Lucke S, Suvorava T, Kojda G, Weber AA, Sorgel F, Levkau B, Ergun S, Fischer JW (2010) Inhibition of hyaluronan synthesis accelerates murine atherosclerosis: novel insights into the role of hyaluronan synthesis. Circulation 122:2313-2322

26. Nieuwdorp M, Meuwese MC, Vink H, Hoekstra JB, Kastelein JJ, Stroes ES (2005) The endothelial glycocalyx: a potential barrier between health and vascular disease. Curr Opin Lipidol 16:507511

27. Oberleithner H (2005) Aldosterone makes human endothelium stiff and vulnerable. Kidney Int 67:1680-1682

28. Oberleithner H, Callies C, Kusche-Vihrog K, Schillers H, Shahin V, Riethmuller C, MacGregor GA, de Wardener HE (2009) Potassium softens vascular endothelium and increases nitric oxide release. Proc Natl Acad Sci U S A 106:2829-2834

29. Oberleithner H, Kusche-Vihrog K, Schillers H (2010) Endothelial cells as vascular salt sensors. Kidney Int 77:490-494

30. Oberleithner H, Riethmuller C, Schillers H, MacGregor GA, de Wardener HE, Hausberg M (2007) Plasma sodium stiffens vascular endothelium and reduces nitric oxide release. Proc Natl Acad Sci U S A 104:16281-16286

31. Pesen D, Hoh JH (2005) Micromechanical architecture of the endothelial cell cortex. Biophys J 88:670-679

32. Rehm M, Bruegger D, Christ F, Conzen P, Thiel M, Jacob M, Chappell D, Stoeckelhuber M, Welsch U, Reichart B, Peter K, Becker BF (2007) Shedding of the endothelial glycocalyx in patients undergoing major vascular surgery with global and regional ischemia. Circulation 116:1896-1906

33. Siegel G, Walter A, Kauschmann A, Malmsten M, Buddecke E (1996) Anionic biopolymers as blood flow sensors. Biosens Bioelectron 11:281-294

34. Singh A, Satchell SC, Neal CR, McKenzie EA, Tooke JE, Mathieson PW (2007) Glomerular endothelial glycocalyx constitutes a barrier to protein permeability. J Am Soc Nephrol 18:2885-2893

35. Thi MM, Tarbell JM, Weinbaum S, Spray DC (2004) The role of the glycocalyx in reorganization of the actin cytoskeleton under fluid shear stress: a "bumper-car" model. Proc Natl Acad Sci U S A 101:16483-16488

36. Titze J, Machnik A (2010) Sodium sensing in the interstitium and relationship to hypertension. Curr Opin Nephrol Hypertens 19:385-392

37. VanTeeffelen JW, Brands J, Jansen C, Spaan JA, Vink H (2007) Heparin impairs glycocalyx barrier properties and attenuates shear dependent vasodilation in mice. Hypertension 50:261-267

38. Waanders F, de Vries LV, van GH, Hillebrands JL, Laverman GD, Bakker SJ, Navis G (2011). Aldosterone, from (patho)physiology to treatment in cardiovascular and renal damage. Curr Vasc Pharmacol (in press)

39. Weinbaum S, Tarbell JM, Damiano ER (2007) The structure and function of the endothelial glycocalyx layer. Annu Rev Biomed Eng 9:121-167

40. Weinbaum S, Zhang X, Han Y, Vink H, Cowin SC (2003) Mechanotransduction and flow across the endothelial glycocalyx. Proc Natl Acad Sci U S A 100:7988-7995 